\title{
Performance Evaluation of An Innovative Column Attachment Ventilation
}

\author{
Haiguo Yin, Angui $\mathrm{Li}^{*}$, Linna $\mathrm{Li}$, and Rui $\mathrm{Wu}$ \\ Xi'an University of Architecture and Technology, School of Building Services Science and Engineering, 710055 Xi'an, China
}

\begin{abstract}
An innovative column attachment ventilation (CAV) was proposed for heating, ventilating and air-conditioning (HVAC) systems and its performance was evaluated through experimental investigation and numerical modeling. Airflow pattern, air temperature distribution, air diffusion performance index (ADPI), predicted mean vote (PMV), and draught rate (DR), were used as the performance indicators to investigate the air distribution performance. The ventilation effectiveness for heat removal in the CAV mode was compared with a conventional mixing ventilation (MV). The results showed that the discharged air from the linear slot diffuser can attach to the column and enter into the occupied zone creating air lake phenomenon. The airflow spread over the floor in a radial pattern behaved as a stratified air distribution like displacement ventilation (DV), providing good air quality and comfort level for occupants. Moreover, the heat removal effectiveness in the CAV was found to be higher than in the MV, i.e. 1.32 in the C-CAV and 1.29 in the S-CAV modes. The column attachment ventilation can achieve thermal comfort in the occupied zone without local discomfort caused by high vertical temperature difference and draught, and this ventilation strategy could be expected as a new and efficient air distribution pattern for different HVAC applications.
\end{abstract}

\section{Introduction}

With the development of building technologies and the demand for economic progress, large spaces are emerging in the civil and industrial fields such as shopping centers, subway stations, airport terminals, and factory halls. High performance large space buildings must ensure an acceptable indoor environmental quality, by providing higher indoor air quality and comfort levels for their occupants. Furthermore, the energy consumption of large space buildings is very high due to its large height and span, dense occupancy, and long hours of operation [1]. Therefore, advanced heating, ventilating and air conditioning (HVAC) systems should not only promote a healthy and comfortable environment for occupants but should also contribute to energy conservation [2-4].

Mixing ventilation (MV), a conventional air distribution, is widely used in different types of buildings [5]. However, the international energy agency (IEA) Annex 26 defined large space as an enclosed ventilated air space partly occupied and containing various contaminant and heat sources. The air distribution should, therefore, be well-planned and controlled to ensure an acceptable indoor environment in the occupied zone without the need for excessive airflow rates [6]. Therefore, the use of MV mode in large space buildings will result in energy wastage and poor air quality because of conditioning the unoccupied upper zone $[4,7]$. Displacement ventilation (DV) can be an efficient alternative to MV, in which supply air with a low speed (typically $<0.5 \mathrm{~m} / \mathrm{s}$ ) is directly inserted into the occupied zone $[8,9]$. Therefore, a higher ventilation efficiency and better air quality can be achieved as compared to the use of the MV system [10, 11]. However, the proximity between the air supply and occupants may cause discomfort due to cold draught, which results that the DV system can be used for space with a cooling load up to $40 \sim 50 \mathrm{~W} / \mathrm{m}^{2}[12,13]$. In addition, DV also has some disadvantages because of its low momentum supply and inefficiency in delivering fresh air with long distances from the supply terminal [14]. When applied to large space buildings with higher cooling load and larger building span, DV systems are mostly combined with other systems such as cooled ceiling systems [15] and radiant floor cooling systems [16]. Another problem limiting the application of DV is space consideration. To maximize system efficiency, the typical locations of supply outlets are on the low side wall or floor. These supply outlets typically take up considerably more occupied space than the outlets used in the MV system [17].

On the other hand, large space buildings are often found having complicated structures, and their enclosures may also be complex and have functional partitions. These physical characteristics of large space buildings would have a great influent on the air distribution in existing ventilation modes as compared to small space buildings. However, large spaces are often found in numerous structural forms where novel ideas

* Corresponding author: liag@xauat.edu.cn 


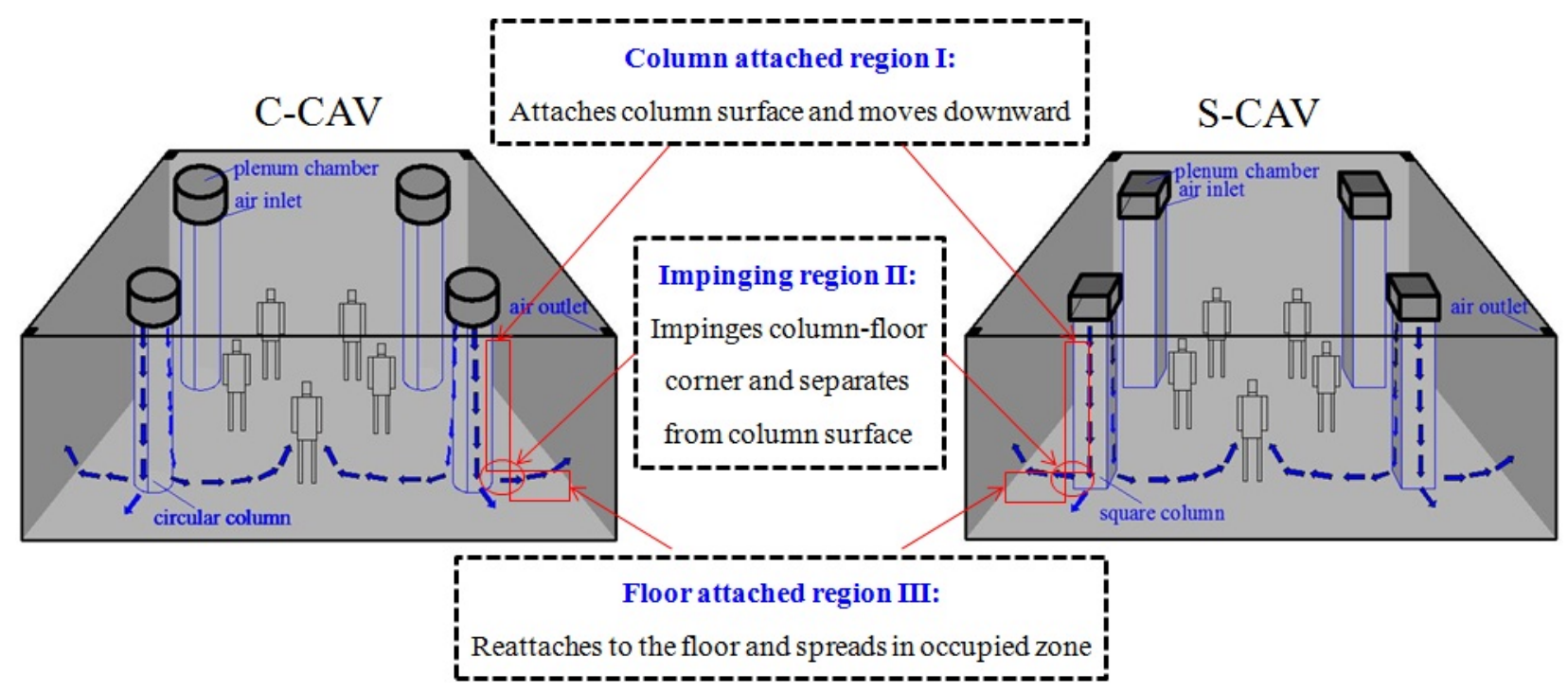

Fig. 1. Conceptual airflow diagram of C-CAV and S-CAV.

are tried and tested. For buildings with a column/pillar frame structure, there are many evenly distributed columns that divide the large space into smaller volumes. By controlling each small space environment, overall control of the large space environment can be achieved, thereby reducing the impact of spatial dimension on the ventilation mode. From the perspective of integration of ventilation strategies and building structure, a new type of air distribution - column/pillar attachment ventilation (CAV/PAV) was proposed (Fig. 1).

As shown in Fig. 1, the CAV works by mounting a ring-shaped or ambulatory-shaped slot inlets on the ceiling, and then the supply air jet at a high momentum is discharged downward and attached to the circular or square column surface due to the Coanda effect, which can lead to a lower degree of mixing with the unoccupied upper zone air (see region I). The supply jet is still attached to the column until it reaches the floor level, where it strikes the floor and then quickly loses momentum from the supply (see region II). Similar to DV, the supply air will spread over the floor in a radial pattern to form an air lake or air pool in the occupied zone (see region III). The ubiquitous columns in large spaces enable the CAV to separately and uniformly deliver more fresh air and energy to the occupied zone, achieving better indoor air quality and higher ventilation efficiency than MV systems, and handling larger space load than DV systems. Furthermore, the CAV also has the potential to overcome the drawbacks of take-up effective occupied space when configured DV air diffusers. Consequently, this ventilation strategy is believed to combine the advantages of both the MV and DV systems [18].

This paper aims to introduce the concept of column attachment ventilation when it operates in a large space building with a column structure. Both experimental and numerical methods were used to investigate the air distribution characteristics of circular-based CAV (C$\mathrm{CAV}$ ) and square-based CAV (S-CAV) modes in specific case studies. Six indices were used to evaluate the ventilation performance. The heat removal effectiveness of CAV was also compared with an MV system. The results could be useful to guide the applications of CAV in different HVAC systems.

\section{Methodology}

\subsection{Experimentation}

The experiments are often used to investigate the performance of a specified ventilation mode, which can provide first-hand and reliable information when introducing a new type of air distribution. On the other hand, the use of full-scale space to conduct a comprehensive study of the CAV mode is quite expensive and time-consuming. Therefore, the experiment was carried out in a down-scale enclosure to determine the feasibility of CAV through flow visualization using the tracer-gas technique, which is very effective for characterizing the airflow pattern in large spaces [6].

The test enclosure had dimensions of $4.0 \mathrm{~m}(\mathrm{~L}) \times 4.0$ $\mathrm{m}(\mathrm{W}) \times 3.2 \mathrm{~m}(\mathrm{H})$ and the length and width were $1 / 3$ of the numerical simulation model. Four equally-scaled circular columns $(\phi 0.33 \mathrm{~m} \times 0.83 \mathrm{~m})$ or square columns $(0.33 \mathrm{~m} \times 0.33 \mathrm{~m} \times 0.83 \mathrm{~m})$ were evenly distributed in the enclosure. On the top of the column, there was an air supply device $(0.37 \mathrm{~m} \times 0.37 \mathrm{~m} \times 0.15 \mathrm{~m})$, which was built to improve the uniformity of the outlets by introducing some perforated planes and partition planes. These planes convert the dynamic pressure of the supply air to static pressure. The ring or ambulatory shaped slot outlet was located at the bottom of this device and has a width $b$ of $0.017 \mathrm{~m}$. The vertical distance between the slot outlets and the floor was $0.83 \mathrm{~m}$ (ceiling height). During the visualization experiment, a fabric curtain was placed over the enclosure wall to provide a black background to visualize the white smoke. When the high-temperature smoke generated by the smoke machine was sent to the slot outlet along the air supply duct, its heat had diffused into the supply air, and its temperature had dropped to a temperature substantially consistent with the environment. At the same time, in 
order to capture the overall distribution of airflow along the floor from the top of the room, the enclosure did not have a ceiling to form an enclosed space. Because of this, the experimental test was carried out under isothermal conditions. However, the main purpose of this experiment was to introduce the CAV mode and obtain some airflow characteristics for engineering design, where the isothermal condition was also useful [18].
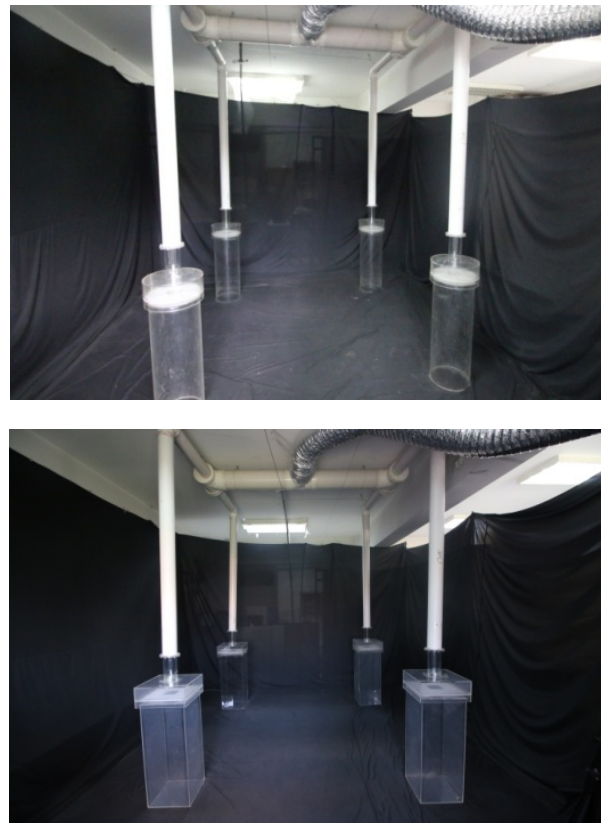

Fig. 2. Layouts of visualization experiments.

\subsection{Computational fluid dynamics simulation}

In order to obtain detailed information on the flow field, thermal comfort and energy consumption, numerical simulations which are less expensive and less time consuming were applied to evaluate the performance of $\mathrm{CAV}$ in the original dimension of a large space building.

Fig. 3 shows the geometrical configurations for CCAV, S-CAV and MV simulations. The physical model in the three ventilation modes was part of a large space building with a typical four-column structure. The dimension was $12.0 \mathrm{~m}(\mathrm{~L}) \times 12.0 \mathrm{~m}(\mathrm{~W}) \times 4.0 \mathrm{~m}$ (ceiling height). The arrangement of the columns and slot outlets was unified with the experimental model, but the size was increased by a factor of three. For MV simulation, the air supply and exhaust diffusers were mounted on the ceiling. The supply air was discharged from the nine inlets $(0.2 \mathrm{~m} \times 0.2 \mathrm{~m})$ with an angle of $60^{\circ}$ from the ceiling towards the floor, while the contaminated air was evacuated from the four outlets $(0.3 \mathrm{~m} \times 0.3 \mathrm{~m})$ located at the corners of the space. According to the layout of a typical shopping center, a total of 32 standing occupants were arranged. The typical metabolic rate of an average adult on standing and light activity was $93 \mathrm{~W} / \mathrm{m}^{2}$ [19]. The Dubois surface area of a $1.73 \mathrm{~m}$ tall and $70 \mathrm{~kg}$ man is $1.8 \mathrm{~m}^{2}$ [20]. The heat generated by each occupant was set to $167.4 \mathrm{~W}$. In addition, 32 lamps were installed on the ceiling of the room as overhead lighting, and the heat generated by each lamp was set to $61.2 \mathrm{~W}$. As a result, the LPD (lighting power density) using the building area method was $13.6 \mathrm{~W} / \mathrm{m}^{2}$ [21]. In addition to the heat load from the internal sources, the heat load was evenly set according to the area on the walls and floor, resulting in a total heat load of $21600 \mathrm{~W}$ ( $150 \mathrm{~W}$ per unit floor area). In order to eliminate these loads, a same supply air temperature and volumetric flow rate were used to ensure the same amount of energy supplied to the room in the three ventilation modes. In the present physical models, the areas of the supply device of C-CAV, SCAV and MV were $0.66,0.84$ and $0.36 \mathrm{~m}^{2}$, respectively, so the corresponding supply velocities were 2.0, 1.57 and $3.67 \mathrm{~m} / \mathrm{s}$, respectively, which were within the recommended ranges. Table 1 summarizes the major parameters for each simulated case.

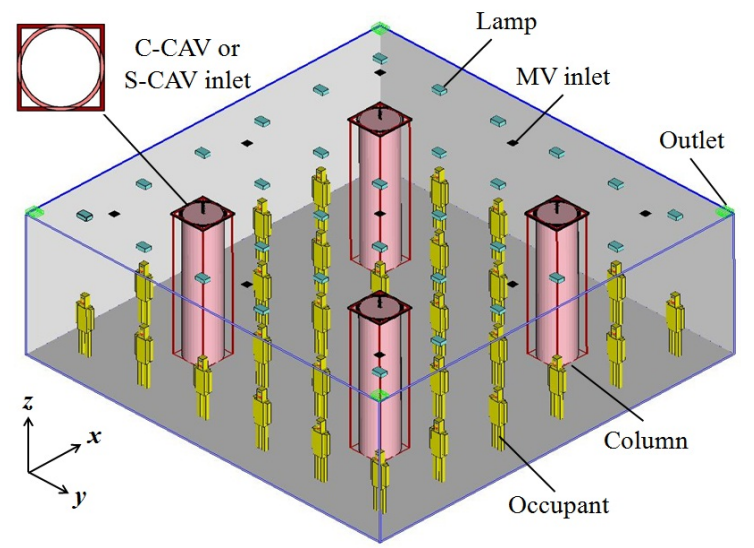

Fig. 3. Geometrical configuration of physical model for three ventilation mode simulations.

The presence of different internal heat sources makes the configuration of the domain complex, and Airpak was chosen due to its simplicity for handling such features. Non-uniform grid distribution was applied. A finer grid was chosen within the vicinity of the inlet, outlet, column, and exterior wall, and a coarser grid was constructed away from these regions. After the gridindependence tests, the grids with hexahedral cells for CCAV, S-CAV, and MV were 2,790,541, 2,867,989 and

Table 1. Major parameters used in the simulations.

\begin{tabular}{|c|c|c|c|c|c|c|c|c|c|c|}
\hline Scheme & $t_{\mathrm{s}}\left({ }^{\circ} \mathrm{C}\right)$ & $u_{\mathrm{s}}(\mathrm{m} / \mathrm{s})$ & $A_{\mathrm{s}}\left(\mathrm{m}^{2}\right)$ & $V_{\mathrm{s}}\left(\mathrm{m}^{3} / \mathrm{h}\right)$ & $Q_{\mathrm{o}}(\mathrm{W})$ & $Q_{1}(\mathrm{~W})$ & $Q_{\mathrm{w}}(\mathrm{W})$ & $Q_{\mathrm{f}}(\mathrm{W})$ & $Q_{\mathrm{t}}(\mathrm{W})$ & $q\left(\mathrm{~W} / \mathrm{m}^{2}\right)$ \\
\hline C-CAV & \multirow{3}{*}{15} & 2.0 & 0.66 & \multirow{3}{*}{4752} & \multirow{3}{*}{5357} & \multirow{3}{*}{1958} & \multirow{3}{*}{8163} & \multirow{3}{*}{6122} & \multirow{3}{*}{21600} & \multirow{3}{*}{150} \\
\hline S-CAV & & 1.57 & 0.84 & & & & & & & \\
\hline MV & & 3.67 & 0.36 & & & & & & & \\
\hline
\end{tabular}

Note: $t_{\mathrm{s}}$ is the supply air temperature, $u_{\mathrm{s}}$ is the supply air velocity, $A_{\mathrm{S}}$ is the total air supply area, $V_{\mathrm{s}}$ is the supply volumetric flow rate, $Q$ represents the heat production, the subscript $\mathrm{o}, 1, \mathrm{w}$, and f denote occupants, overhead lighting, surrounding walls, and floor, and $Q_{\mathrm{t}}$ is the total heat load in the space, and $q$ is the total heat load per floor area. 
2,709,957, respectively. The Reynolds Stress Model (RSM) model based on the commercial program ANSYS Fluent was used to perform the simulation. This model developed by Gibson and Launder [22] explicitly solve the transport equations of Reynolds stresses, and nonisotropic characteristics of the model play a significant role in the flow with a swirl or strong curvatures [23]. Prior to the numerical simulation, the model was first validated by the experimental data. The deviation between the experimental data and the numerical results using the RSM-IP model were $5.5 \%$ in the vertical column-attached zone and $16.6 \%$ in the horizontal floorattached zone [24]. Therefore, the RSM-IP model used was considered to be acceptable for simulating airflow and thermal environment in large space buildings.

The computations used the finite-volume method and the second-order upwind for the convection terms. The discretized equations were solved with the SIMPLE algorithm. A standard wall function was applied to describe the turbulent flow properties in the near wall region. The buoyancy effect was considered by the Boussinesq model. The converged residuals of variable $P, u_{i}, k, \varepsilon$ and $\overline{u_{i} u_{j}}$ were less than $10^{-3}$, and the energy was less than $10^{-6}$. During the computation, the inlet flow rate and outlet flow rate were also monitored. The difference was less than $0.2 \%$, which also demonstrated the convergence of the computation.

\subsection{Evaluation indices}

An important objective of the ventilation system is to create an environment with reasonable air distribution, efficient energy consumption, and acceptable thermal comfort. The indices used to evaluate the performance of column attachment ventilation are as follows.

1. Airflow pattern.

2. Air temperature distribution.

3. Heat removal effectiveness.

4. Air diffusion performance index (ADPI).

5. Predicted mean vote (PMV).

6. Draught rate (DR).

According to ASHRAE 55 [25], the air velocity and air temperature were analyzed at the ankle level $(y=0.1$ $\mathrm{m})$, waist level $(y=1.1 \mathrm{~m})$, and head level $(y=1.7 \mathrm{~m})$ for standing occupants. The air velocity and air temperature of the occupied zone were the numerical averages of the three levels. For standing occupants, the PMV was analyzed at a level of $y=1.1 \mathrm{~m}$. The ADPI was developed as a way to quantify the comfort level for a space conditioned by an MV system for cooling [26], but the index can also be used to evaluate the performance of $\mathrm{CAV}$ because the concept is familiar to HVAC specialists and researchers. The same as PMV, the ADPI was also calculated at $y=1.1 \mathrm{~m}$. To assess the local cooling of the body caused by air movement, DR was analyzed at $y=0.1 \mathrm{~m}$ (ankle level), which was considered to be the most sensitive part of an occupant in the CAV mode [19]. A representative 20 points were chosen to calculate the values of these indices at different levels (Fig. 4). In addition, two vertical profiles were used to further evaluate the performance of CAV and MV modes. The profile of $x=3.0 \mathrm{~m}$ represented the middle section of the column, and $x=6.0 \mathrm{~m}$ was the middle section of the space.

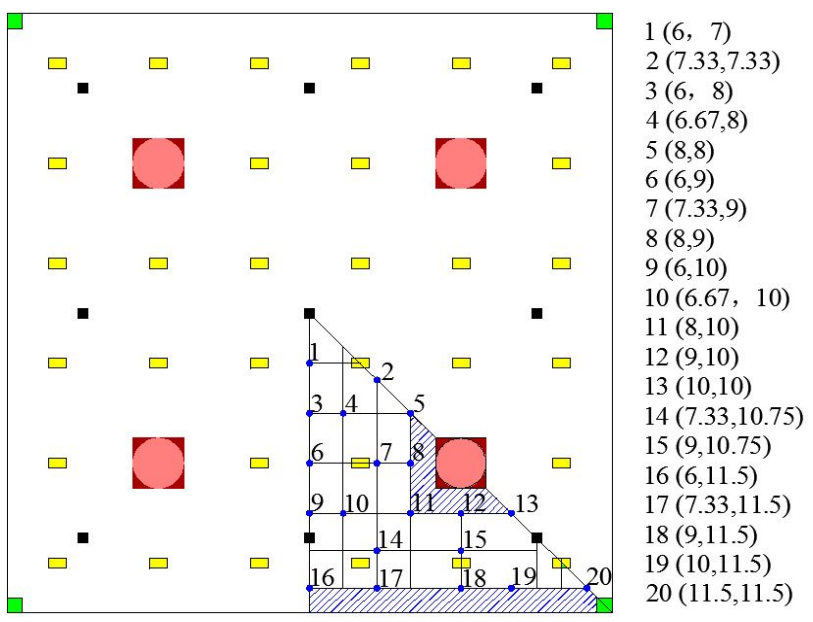

Fig. 4. Layout of the chosen points in simulation results analysis.

\section{Results and discussion}

\subsection{Airflow pattern}

Fig. 5 shows the airflow pattern of CAV in the experiment and that of section $x=3.0 \mathrm{~m}, y=1.1 \mathrm{~m}$ in the simulation. Both the experimental and numerical results indicated that the supply air at a high momentum was discharged downwards and attached to the column, impinging the floor and spreading over it. Similar to DV, the airflow pattern in CAV was characterized by stratified flow, creating an air lake phenomenon in the occupied area, which provided the occupied zone with fresher and cooler air than the other zones. The average air velocity of C-CAV and S-CAV within the occupied zone was $0.21 \mathrm{~m} / \mathrm{s}$ and $0.19 \mathrm{~m} / \mathrm{s}$, respectively, which results in an acceptable environment for occupants.

The temperature distribution at the sections of $\mathrm{x}=3.0$ $\mathrm{m}, \mathrm{x}=6.0 \mathrm{~m}$ and $\mathrm{y}=1.1 \mathrm{~m}$ is shown in Fig. 6. In vertical temperature profiles of the $\mathrm{CAV}$ mode, a temperature gradient was observed along the height of the space. The air temperature in the occupied zone was significantly lower than the upper zone of the space $(\mathrm{z}>1.8 \mathrm{~m})$, which can lead to a higher ventilation efficiency. The air temperatures at two vertical profiles almost showed the same value for both C-CAV and S-CAV modes. At the height level of $y=1.1 \mathrm{~m}$, it can be seen that the air temperatures of the two CAV modes were almost maintained at the same level $\left(25^{\circ} \mathrm{C}\right.$ to $\left.26^{\circ} \mathrm{C}\right)$, resulting in a uniform temperature distribution at different locations to improve thermal comfort. It can also be seen that the air temperature in the MV mode was higher than that in the CAV mode. The average air temperatures within the occupied zone for C-CAV, S-CAV and MV were $25.1{ }^{\circ} \mathrm{C}, 25.4{ }^{\circ} \mathrm{C}$, and $28.8{ }^{\circ} \mathrm{C}$, respectively. This indicated that the cooling energy required to achieve the same spatial temperature in the MV space was larger than that in the CAV mode. 

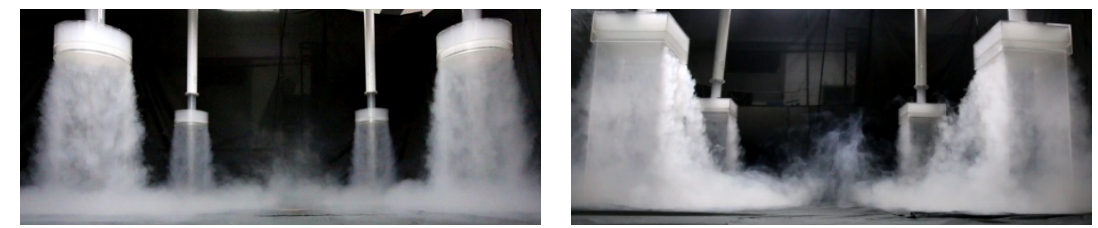

(a)
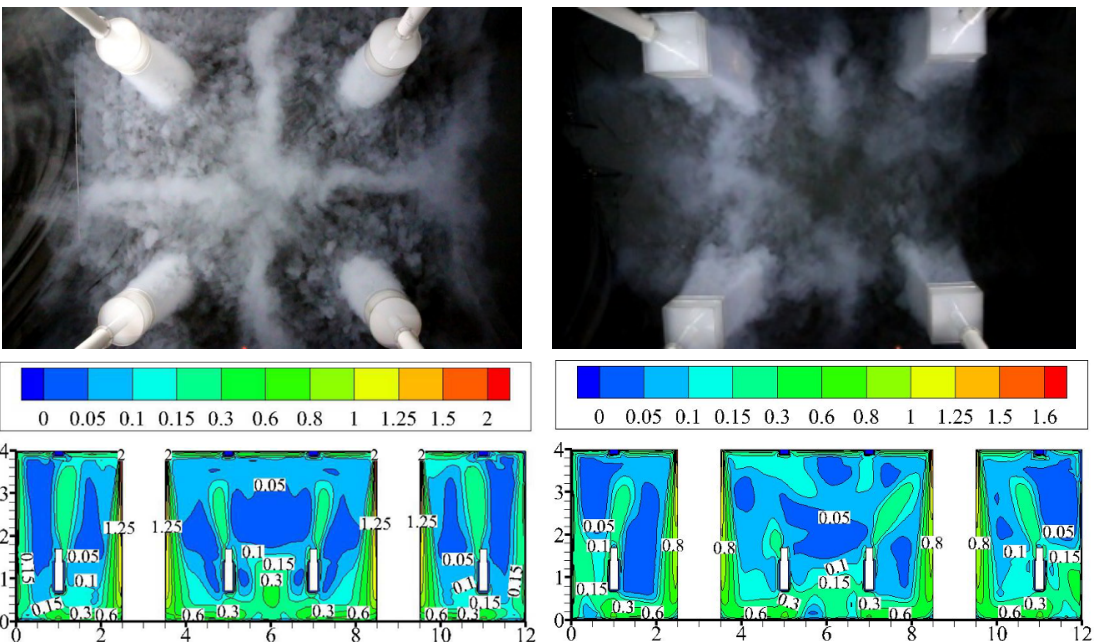

(b)
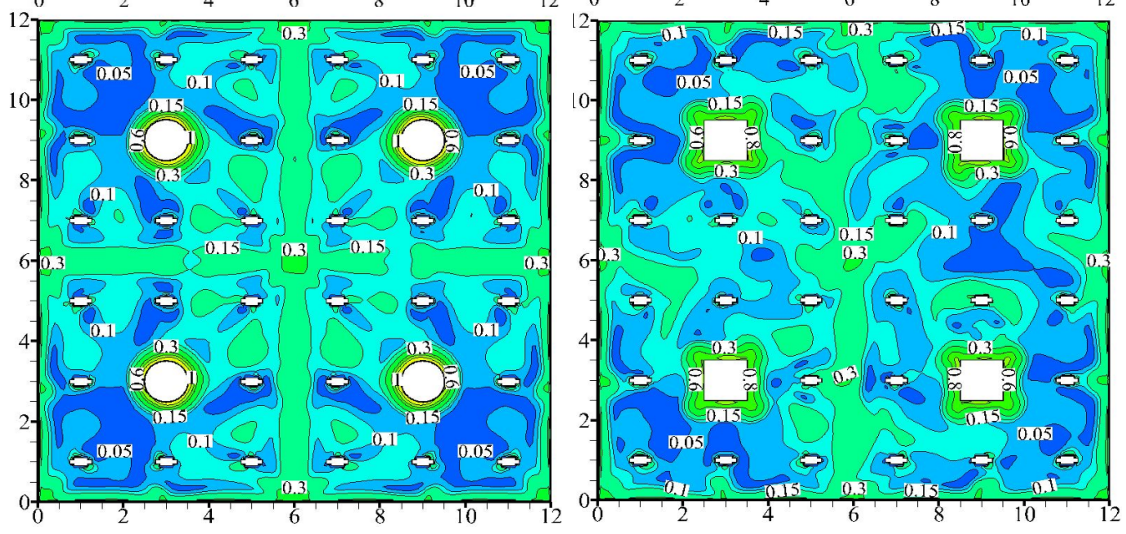

Fig. 5. Airflow patterns of C-CAV and S-CAV in (a) visualization experiment and (b) numerical simulation.

\subsection{Air temperature distribution}

(a)
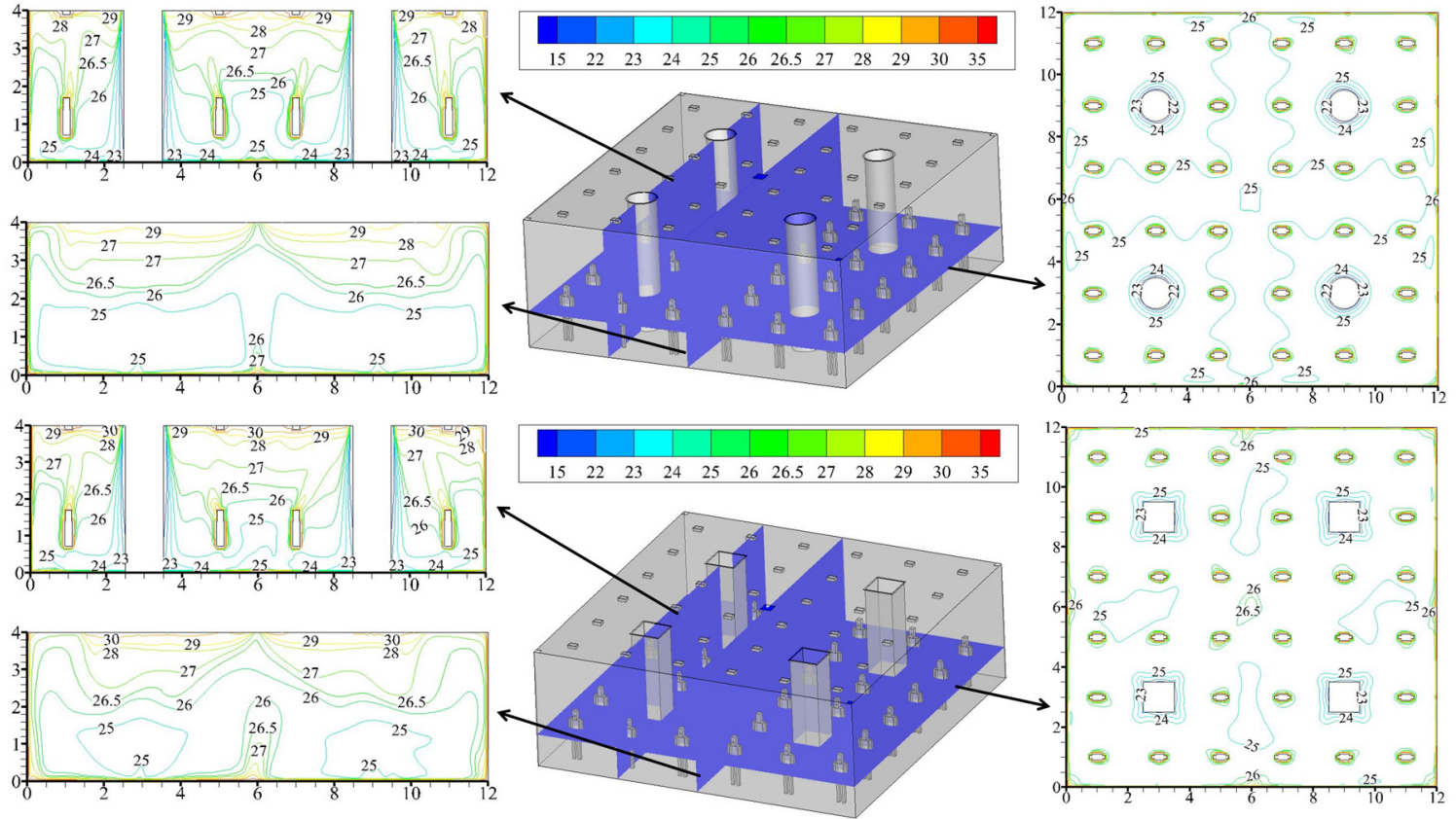

(b)

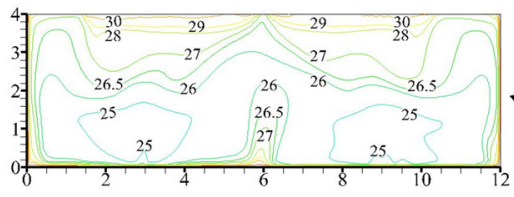


(c)

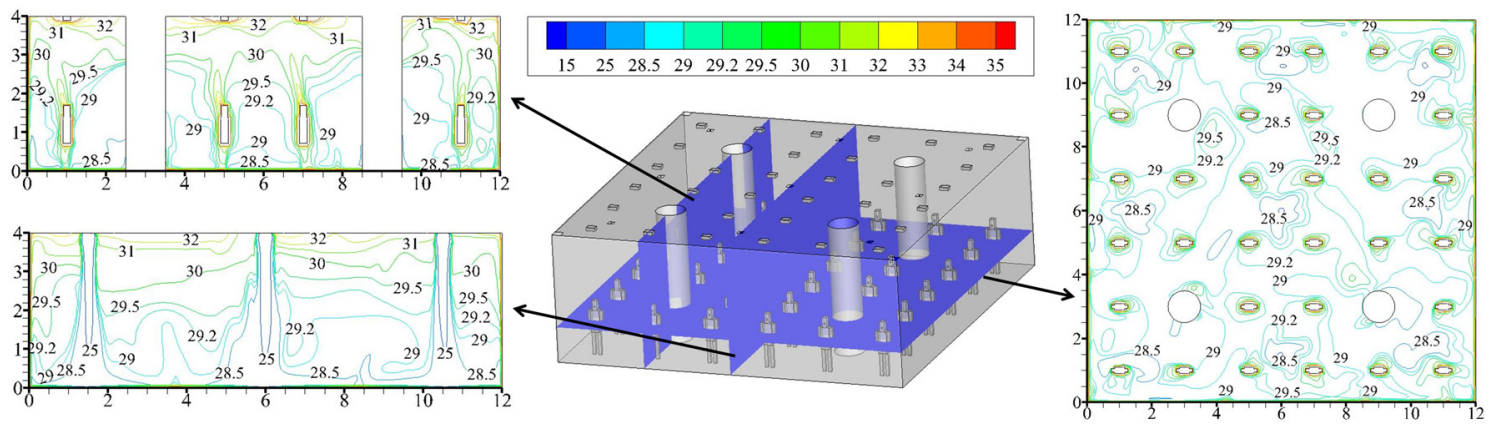

Fig. 6. Air temperature distribution at $x=3.0 \mathrm{~m}, x=6.0 \mathrm{~m}$ and $y=1.1 \mathrm{~m}$ in (a) C-CAV, (b) S-CAV, and (c) MV mode.

Fig. 7 presents a comparison of the mean air temperatures at different spatial heights in the C-CAV, S-CAV and MV modes. It can be seen that the shape of the vertical temperature distribution was approximately the same as that in the three ventilation modes. This is because the same scheme of upper zone mounted supply and exhaust diffusers were used in all three modes. However, the air temperatures at different heights in the MV space were almost the same as that in the occupied zone, which indicated a perfect mixing within this zone. In contrast, an increase in air temperature along the height of the occupied zone can be observed in the CAV mode, where the temperature gradient of C-CAV and SCAV was 3.1 and 2.4 times of that in the MV mode, respectively. On the other hand, the vertical air temperature difference between $1.7 \mathrm{~m}$ and $0.1 \mathrm{~m}$ was $1.1{ }^{\circ} \mathrm{C}$ for the C-CAV and $0.9{ }^{\circ} \mathrm{C}$ for the S-CAV. There was no local discomfort caused by an abnormally high vertical temperature difference between the head and feet $\left(4^{\circ} \mathrm{C}\right.$ for standing occupants in ASHRAE 55).

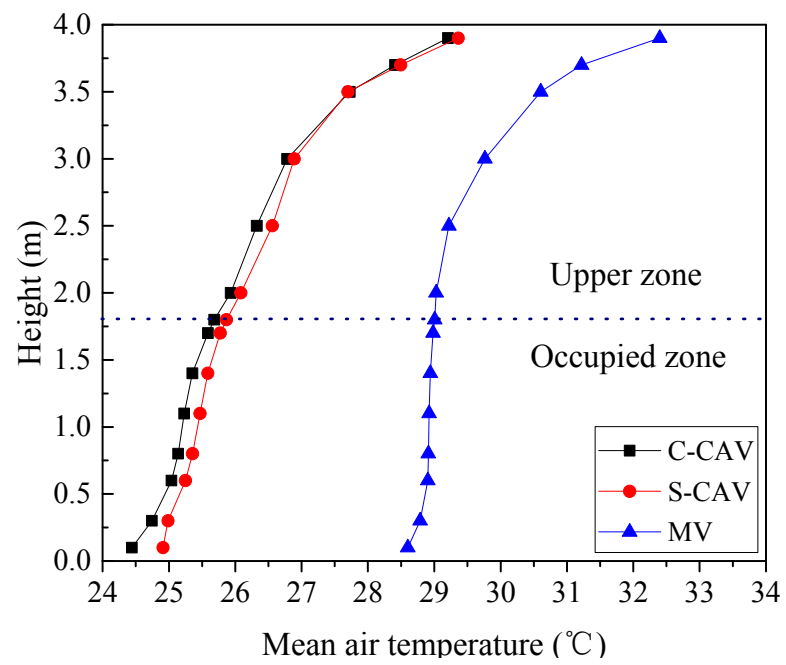

Fig. 7. Mean air temperature distribution at different heights of the space in three ventilation modes.

\subsection{Heat removal effectiveness}

Knowing the air temperature in the occupied zone, in the supply airflow, and in the exhaust airflow, it is possible to calculate the heat removal effectiveness [27] by using the following equation.

$$
\varepsilon_{\mathrm{t}}=\frac{t_{\mathrm{e}}-t_{\mathrm{s}}}{t_{\mathrm{o}}-t_{\mathrm{s}}}
$$

where $\varepsilon_{\mathrm{t}}$ is the ventilation effectiveness for heat removal, $t_{\mathrm{e}}$ is the exhaust air temperature, $t_{\mathrm{s}}$ is the supply air temperature, and $t_{\mathrm{o}}$ is the average air temperature within the occupied zone.

The exhaust air temperature was calculated as the numerical average of all outlets, i.e. $28.4{ }^{\circ} \mathrm{C}, 28.4{ }^{\circ} \mathrm{C}$ and $30.9{ }^{\circ} \mathrm{C}$ for $\mathrm{C}-\mathrm{CAV}, \mathrm{S}-\mathrm{CAV}$, and $\mathrm{MV}$, respectively. Therefore, the ventilation efficiency for the heat removal in the C-CAV, S-CAV and MV mode was 1.32, 1.29 and 1.15 , respectively. Compared to $\mathrm{MV}$, the CAV was more energy efficient and improved efficiency by $14.8 \%$ and $12.2 \%$ in the C-CAV and S-CAV modes, respectively.

\subsection{Air diffusion performance index (ADPI)}

The ADPI is defined as the percentage of locations where measurements are taken, that meet these specifications for effective draft temperature and velocity. High ADPI values generally correlate to high space thermal comfort levels with the maximum obtainable value of $100 \%$ [26]. The ADPI of the chosen points was calculated at $y=1.1 \mathrm{~m}$ level. The ADPI values in the C-CAV, S-CAV and MV modes met the design requirement $(\geq 80 \%$ ), which were $80 \%, 85 \%$, and $100 \%$, respectively.

\subsection{Predicted mean vote (PMV)}

The PMV in different ventilation modes was calculated based on the predicted mean air velocity and temperature at $y=1.1 \mathrm{~m}$ level. For the C-CAV mode, the calculated PMV was 0.66 , which conforms to the class $\mathrm{C}$ category $(-0.7<$ PMV $<+0.7)$ as defined in ISO 7730 [19]. The PMV level was slightly higher in the S-CAV mode, where the calculated PMV was 0.75 , which means a slightly warm environment in the occupied zone. The large PMV value was mainly due to the high air temperature of the occupied zone in the S-CAV mode. For the MV mode with the highest occupied zone temperature of $28.8{ }^{\circ} \mathrm{C}$, the calculated PMV value was even higher (i.e. 1.48), and the average thermal sensation was between slightly warm and warm. In this study, in order to achieve a comfortable thermal environment for occupants, the average air temperature within the occupied zone was preferably around $25^{\circ} \mathrm{C}$. 


\subsection{Draught rate (DR)}

Based on ISO 7730, the comfortable thermal environment should satisfy the requirements for both the general thermal comfort and local thermal comfort. The aforementioned section showed that the CAV has an air distribution similar to the DV in the occupied zone. Therefore, DR was employed to demonstrate that the CAV can avoid local thermal discomfort caused by draught, as shown in Fig. 8. The DR level in the CAV was higher than that in the MV mode. However, the requirements of category B for DR in ISO 7730 was less than $20 \%$. The DR levels in both C-CAV and S-CAV mode were lower than this value except the vicinities of columns and floor. At the $0.1 \mathrm{~m}$ level in the C-CAV mode, the DR values of the chosen points ranged from $6.3 \%$ to $25.9 \%$ with an average of $16.2 \%$. The range and average in the S-CAV mode were $2.2 \% \sim 21.4 \%$ and $14.2 \%$, respectively. According to the above results, the air velocities in the S-CAV and C-CAV modes were substantially the same, but the air temperature in the SCAV mode was higher than that in the C-CAV mode. This indicated that a lower DR could be achieved by increasing the air temperature within the occupied zone, but this was not conducive to improve the PMV value. It was necessary, during the design of the CAV system, to fully consider the general thermal comfort, local thermal comfort, and other indices.

(a)

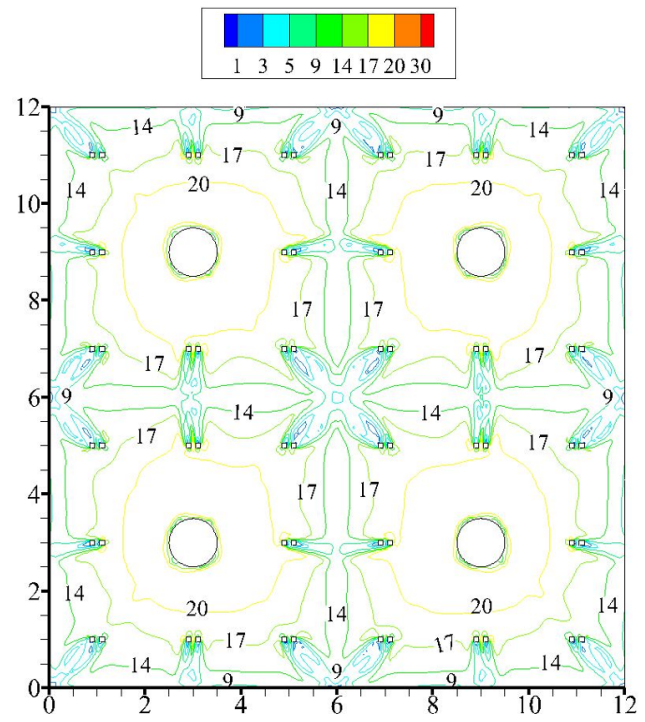

(b)

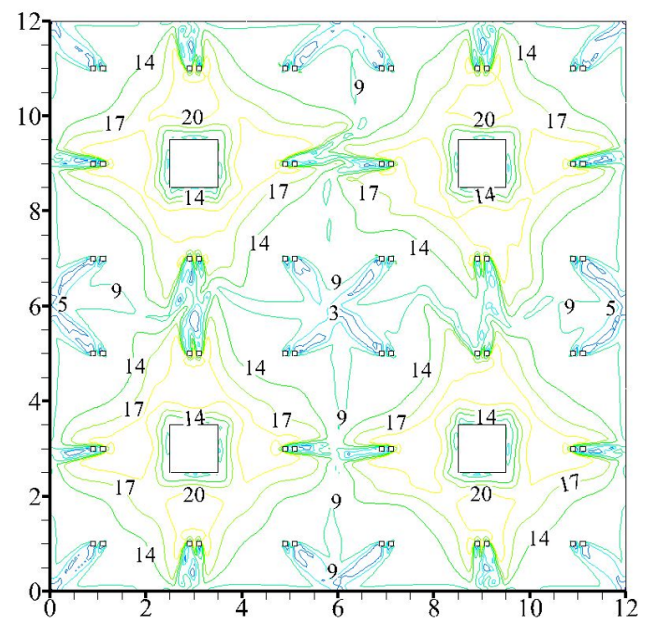

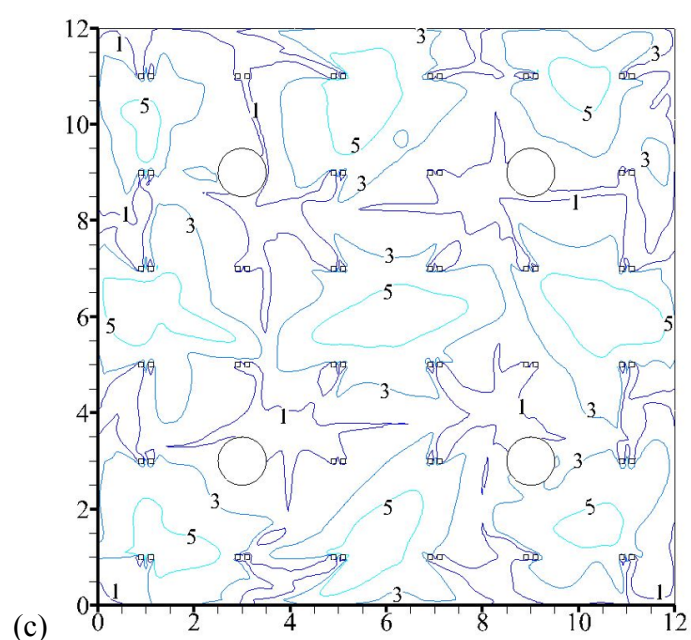

Fig. 8. DR distribution at $y=0.1 \mathrm{~m}$ in (a) C-CAV, (b) S-CAV, and (c) MV mode.

\section{Conclusions}

An innovative column attachment ventilation was proposed, and the performance of the C-CAV and SCAV modes was investigated by employing both experimental and numerical techniques. When operated in the occupied zone, the CAV mode was similar to DV mode, and can result in higher energy utilization when compared with the MV mode in a large space building with column structure.

The performance of C-CAV, S-CAV, and MV was compared by considering airflow pattern, air temperature distribution, heat removal effectiveness, ADPI, PMV, and DR. The uniformities of velocity and temperature within occupied zone were satisfactory in both C-CAV and S-CAV modes with the ADPI of $80 \%$ and $85 \%$, respectively. The supply air was directly delivered to the occupied zone without over conditioning the upper zone of the room. Compared with the conventional MV mode, the energy required to achieve the same spatial temperature in the CAV mode was lower, and the ventilation effectiveness was increased by $14.8 \%$ in the C-CAV mode and $12.2 \%$ in the S-CAV mode.

For the C-CAV mode, the PMV corresponds to category C while DR corresponds to category B of thermal environment in ISO 7730. It indicated a general thermal comfort in the occupied zone without local discomfort caused by draught. The occupants in the SCAV mode were also not exposed to draught risk, but they were subjected to a slightly warm environment $(\mathrm{PMV}=0.75)$. Further research was needed to investigate the effects of different parameters such as supply air temperature, air velocity, and slot outlet width to determine the optimal configuration of the CAV mode.

This study was jointly funded by the National Natural Science Foundation of China (No. 51408477), the Innovative Talent Promotion Plan of Shaanxi Province (No. 2018KJXX-087), and the Natural Science Foundation of Education Department of Shaanxi Province (No. 17JK0450).

\section{References}


1. L. Zhang, X. Liu, K. Zhao, Y. Jiang, Entransy analysis and application of a novel indoor cooling system in a large space building, Int. J. Heat Mass Tran. 85, 228-238 (2015)

2. T. Karimipanah, H.B. Awbi, B. Moshfegh, The air distribution index as an indicator for energy consumption and performance of ventilation systems, J. Hum. Environ. Syst. 11, 77-84 (2008)

3. G. Cao, H.B. Awbi, R. Yao, Y. Fan, K. Sirén, R. Kosonen, J.J. Zhang, A review of the performance of different ventilation and airflow distribution systems in buildings, Build. Environ. 73, 171-186 (2014)

4. A.K. Melikov, Advanced air distribution: improving health and comfort while reducing energy use, Indoor air 26, 112-124 (2016)

5. D. Müller, C. Kandzia, R. Kosonen, A. Melikov, P. Nielsen, Mixing Ventilation-Guide on mixing air distribution design, REHVA Guidebook No. 19, Brussels, Belgium: Federation of European Heating, Ventilation and Air Conditioning Associations (2013)

6. P. Heiselberg, S. Murakami, C.-A. Roulet, Ventilation of large spaces in buildings, Final Report IEA Annex 26 (1998)

7. K. Sommer, K. Kabele, M. Kotrbaty, D. Petras, O. Hojer, Energy efficient heating and ventilation of large halls, REHVA Guidebook No. 15, Brussels, Belgium: Federation of European Heating, Ventilation and Air Conditioning Associations (2011)

8. Q. Chen, L. Glicksman, System performance evaluation and design guidelines for displacement ventilation, Atlanta, USA: American Society of Heating, Refrigerating, and Air-Conditioning Engineers (2003)

9. H. Skistad, E. Mundt, P.V. Nielsen, K. Hagström, J. Railio, Displacement ventilation in non-industrial premises, REHVA Guidebook No. 1, Brussels, Belgium: Federation of European Heating, Ventilation and Air Conditioning Associations (2002)

10. H. Awbi, Energy efficient room air distribution, Renew. Energ. 15, 293-299 (1998)

11. Z. Lin, T. Chow, K. Fong, C. Tsang, Q. Wang, Comparison of performances of displacement and mixing ventilations. Part II: indoor air quality, Int. J. Refrig. 28, 288-305 (2005)

12. X. Yuan, Q. Chen, L.R. Glicksman, A critical review of displacement ventilation, ASHRAE Trans. 104, 78 (1998)

13. S.D. Hamilton, K.W. Roth, J. Brodrick, Displacement ventilation, ASHRAE J. 46, 56 (2004)

14. Y. Cheng, Z. Lin, Technical feasibility of a stratum-ventilated room for multiple rows of occupants, Build. Environ. 94, 580-592 (2015)
15. A. Novoselac, J. Srebric, A critical review on the performance and design of combined cooled ceiling and displacement ventilation systems, Energ. Buildings 34, 497-509 (2002)

16. B. Olesen, Radiant floor cooling systems, ASHRAE J. 50, 16-20 (2008)

17. ASHRAE, 2016 ASHRAE HANDBOOK: HVAC systems and equipment, Atlanta, USA: American Society of Heating, Refrigerating, and Air Conditioning Engineers (2016)

18. H. Yin, A. Li, Z. Liu, Y. Sun, T. Chen, Experimental study on airflow characteristics of a square column attached ventilation mode, Build. Environ. 109, 112-120 (2016)

19. ISO, ISO 7730-2005: Ergonomics of the thermal environment-Analytical determination and interpretation of thermal comfort using calculation of the PMV and $P P D$ indices and local thermal comfort criteria, Geneva, Switzerland: International Organization for Standardization (2005)

20. D. Du Bois, E.F. Du Bois, Clinical calorimetry: tenth paper a formula to estimate the approximate surface area if height and weight be known, Arch. Intern. Med. 17, 863-871 (1916)

21. ASHRAE, ANSI/ASHRAE/IES Standard 90.1-2016: Energy Standard for Buildings Except Low-Rise Residential Buildings, Atlanta, USA: American Society of Heating, Refrigerating, and Air Conditioning Engineers (2016)

22. M. Gibson, B. Launder, Ground effects on pressure fluctuations in the atmospheric boundary layer, J. Fluid Mech. 86, 491-511 (1978)

23. J. Moureh, D. Flick, Wall air-jet characteristics and airflow patterns within a slot ventilated enclosure, Int. J. Therm. Sci. 42, 703-711 (2003)

24. H. Yin, R. Wu, T. Chen, Y. Sun, A. Li, Study on Ventilation Effectiveness of Circular Column Attached Displacement Ventilation Mode, Procedia Eng. 205, 3511-3518 (2017)

25. ASHRAE, ANSI/ASHRAE Standard 55-2017: Thermal environmental conditions for human occupancy, Atlanta, USA: American Society of Heating, Refrigerating, and Air Conditioning Engineers (2017)

26. ASHRAE, 2015 ASHRAE HANDBOOK: HVAC applications, Atlanta, USA: American Society of Heating, Refrigerating, and Air Conditioning Engineers (2015)

27. D.W. Etheridge, M. Sandberg, Building ventilation: theory and measurement, Chichester, UK: John Wiley \& Sons Chichester (1996) 